\title{
Impact of a diet diversification and health and nutrition counseling program in Madagascar
}

Emily Owen, MS, RD

Graduate Student, Department of Nutrition and Health Care Management, Appalachian State University, 1179 State Farm Road

Boone, NC 28608

Phone: 828-262-7863; Fax: 828-262-8626

Email: owener@appstate.edu

Zachary J. Farris, PhD

Assistant Professor, Department of Health and Exercise Science, Appalachian State University, 1179 State Farm Road

Boone, NC 28608

Phone: 828-262-3138; Fax: 828-262-8626

Email: farriszj@appstate.edu

Haingoniaina Lalatiana Razoliarivelo, MS

Researcher and Translator, University of Antananarivo, Lot B III4/214 Ter Anosiala

Ambohidratrimo 105, Antananarivo, Madagascar

Phone: +261347027397

Email: arivelolalatiana@gmail.com

Jamie B. Griffin, PhD RDN

Assistant Professor, Department of Nutrition and Health Care Management, Appalachian State University, 1179 State Farm Road

Boone, NC 28608

Phone: 828-262-7863; Fax: 828-262-8626

Email: griffinjb@appstate.edu

Alisha R. Farris, PhD, RDN*

Assistant Professor, Department of Nutrition and Health Care Management, Appalachian State University, 1179 State Farm Road

Boone, NC 28608

Phone: 828-262-7863; Fax: 828-262-8626

Email: farrisar@appstate.edu

*Corresponding author 


\section{Abstract}

Background: Due to lack of resources, especially for mothers and children, Madagascar has high levels of malnutrition. Health promotion and education have shown to be effective in increasing health status in limited-resource areas. This study piloted a tailored, four-week health and nutrition counseling program to improve diet diversity and health promoting practices.

Methods: Twenty child caregivers were recruited from Andasibe, Madagascar, using snowball sampling, and were provided weekly individualized health counseling with education materials by the research team. Diet, health knowledge, and health behaviors were assessed using a quasi-experimental one-group pre/post-test design. Body mass index, midupper arm circumference measurements, and Raman spectroscopy technology assessed nutritional status. Data were analyzed using descriptive statistics and paired sample t-tests to determine changes.

Results: All caregivers were female. More caregivers were within normal limits for Body Mass Index (40\%) than underweight or overweight, and most were within normal limits for mid-upper-arm circumference $(75 \%)$. Significant increases $(\mathrm{p} \leq 0.01)$ were found in caregiver consumption of vitamin A-rich foods, and using treated water to wash fruits and vegetables, though significant increases were not found for children. The majority $(80 \%)$ increased diet diversity. Participants increased their knowledge of nutrition and non-nutritious foods.

Conclusions: Results suggest an individualized approach to health promotion in a limitedresource area can improve diet diversity, knowledge and health practices. Opportunities for further education and research include increasing knowledge of nutrient dense foods, expanding food choice beyond carbohydrate-rich foods, diet diversity importance, and sustaining education efforts beyond project implementation. Strategies highlighted in this research can inform others working in limited-resource areas.

Keywords: diet diversity, health promotion, Madagascar, malnutrition

\section{Introduction}

Malnutrition is responsible for $45 \%$ of all child deaths worldwide (Black et al., 2013) with implications of malnutrition most consequential during pregnancy and the first two years of a child's life (Metta et al., 2014; USAID, 2019). Vitamin A blindness and iron deficiency anemia, two common effects of malnutrition globally, often develop from inadequate intake, and contribute to decreased immunity, cognitive dysfunction, and decreased physical strength (Müller \& Krawinkel, 2005). Conversely, high consumptions of processed foods, which provide increased satiating power for lower cost (Black et al., 2013; Rakotosamimanana et al., 2014), can lead to malnutrition and displace needed nutrients (Black et al., 2013).

Madagascar has the world's fourth highest rate of chronic malnutrition, with almost one child in two under five years of age suffering from stunting (World Bank, 2019). Common in adults as well, $37 \%$ of women of childbearing age suffer from anemia and an estimated $27 \%$ suffer from undernutrition (Sharp et al., 2011). High levels of poverty contribute to food being financially inaccessible or unaffordable (Sharp et al., 2011). Previous studies suggest many Malagasy engage in poverty coping mechanisms, choosing between purchasing food or medications for example, or selling valuable assets (e.g., livestock) to purchase lower cost food (Farris et al., 2019). 
Diet diversity has been associated with increased nutrient intake and better health status in resource limited countries (Kennedy et al., 2013). Research shows that nutrient dense foods are available in Madagascar, but not often consumed (Rakotosamimanana et al., 2014). The traditional diet consists of mostly carbohydrates, supplying $77 \%-79 \%$ of total calories, which is higher than health recommendations. Rice, a culturally important food, is the most commonly consumed carbohydrate. While the consumption of fruits and vegetables can vary widely due to seasonality, a previous study conducted in rural and urban areas reported that consumption remains low regardless of season, varying from $6 \%-21 \%$ of total calories. Plant based proteins are consumed only once per week on average, while animal sourced protein consumption varies from twice per week to not at all (Farris et al., 2019; World Food Program, 2010).

Previous studies have found beliefs about the health benefits of food have a larger influence on consumption than the quality of foods (Rakotosamimanana et al., 2014), and misconceptions about the health value of foods are common (Farris et al., 2019). However, many Malagasy are interested in education on diet diversity and health (Asgary et al., 2015; Farris et al., 2019), and education has been shown to positively influence dietary behavior (Mushaphi et al., 2017). Effective strategies to encourage diet diversity in limited-resource countries have been previously identified and include: comprehensive community-based health education, focusing on types of foods and incorporating familiar foods, incorporating caregivers into education, individualized nutrition counseling, and a combination of communication approaches with repeated reinforcement (Khan et al., 2013; Mushaphi, et al., 2017; Sanchez, 2005; Sethi et al., 2003).

The aim of this study was to pilot a tailored, four-week health and nutrition counseling program to improve diet diversity and health practices of child caregivers in Andasibe, Madagascar. We aimed to test the hypothesis that education would improve diet diversity, health knowledge, and ultimately health status of caregivers and children less than 10 years old. To achieve this goal, we evaluated changes in diet diversity, health knowledge and behaviors of caregivers.

\section{Methods}

This exploratory quasi-experimental one-group design pilot study was conducted in Andasibe, located in the Alaotra-Mangoro region of eastern Madagascar, surrounded by several protected natural wildlife and forest reserves. The survey methodology used for this study followed previous studies that provided education in low income, resource limited countries (Asgary et al., 2015; Farris et al., 2019; Rakotosamimanana et al., 2014), with a survey approach followed by a brief open-ended discussion.

\section{Participants and setting}

Participants were recruited using a snowball sampling method from a village of approximately 400 households with 5,000 inhabitants (Association Mitsinjo, 2019). Inclusion criteria included women under 70 years who were primary caregivers for a child(ren) aged $0-10$. Permission was granted from the Ministry of Health and the village mayor. All participants granted verbal consent. The study was approved by Appalachian State University Institutional Review Board. 


\section{Data collection}

Data collection occurred at the first and last week of June 2019. Measures were included to assess health status, diet diversity, and health knowledge and behaviors of caregivers using a pre/posttest design. In addition to the research team, the study team also included one native Malagasy (HLR) who was trained in survey protocol and interview techniques. To accommodate for variability in literacy level, the survey was read aloud in Malagasy to each participant. Survey response time was between 15 to 30 minutes. Responses were translated into English by HLR during the interview, and then recorded verbatim in English onto paper surveys.

Baseline measurements for nutritional status were assessed using height and weight to calculate Body Mass Index (BMI), mid-upper-arm circumference (MUAC). For BMI, scores of less than 18.5 were classified as underweight, 18.5-24.9 as within normal limits, and 25-29.9 as overweight, and 30 or more as obese. For MUAC, less than $24 \mathrm{~cm}$ was classified as low. Indicators of vitamin A status were measured for both participants and their children before and after the intervention based on simple yes/no questions about intake of relevant foods. In addition, the Resonance Raman Spectroscopy (RRS) technology was used to measure carotenoid status in skin (Zidichouski et al., 2009) before and after intervention. For consistency of results, the Pharmanex ${ }^{\circledR}$ BioPhotonic Scanner (S3) device was calibrated each day per device instructions. The RRS scores were categorized according to the RRS S3 scanner manual. Scores of $<10,000$ were classified as less than low intake; 10,000 - 29,000 classified as low intake; 30,000 - 49,000 classified as moderate intake; 50,000 - 90, 000 classified as above average intake.

Diet diversity was assessed both participants and their children at baseline and endline, using a previously validated dietary diversity questionnaire (Ruel et al., 2010). Participants were asked to recall the foods and drinks they consumed in the past 24 hours. Items were categorized into nine food groups with a resulting numeric score given for consumption of foods in each category (Kennedy et al., 2013). Lastly, health knowledge and behaviors were assessed using previously validated questionnaires (Farris et al., 2019; Rakotosamimanana et al., 2014; Headrick et al., 2014) comprised of three main sections: 1) food practices including food selection, food preparation, and hygiene practices, 2) beliefs around food and health, and 3) agriculture and economic practices. Five open-ended questions evaluated program acceptability and behavior changes not captured with the survey.

\section{Nutrition education}

The four-week health and nutrition counseling program, Salama Fahasalamana (translation: Hello Health) included 30-minute individualized nutrition instruction via weekly counseling sessions (Table 1). The individualized counseling (based upon the initial assessment) comprised of verbal discussion with visuals to demonstrate the recommended size and type of foods to consume, based off the World Health Organization dietary recommendations (World Health Organization, 2020), and culturally normative foods, in order to increase diet diversity. Implementation strategies were to incorporate fruits and vegetables into predominantly rice meals, to remain culturally appropriate.

Handouts were translated into Malagasy and reviewed by two bilingual persons to assure translational accuracy and cultural appropriateness. The handouts were utilized to focus messaging around the following topics: 
Handout 1. (for caregivers with children aged 0-1): breastfeeding, complementary foods, encouraging soft fruits and vegetables, food and handwashing, and encouraging vitamin rich colorful foods.

Handout 2. (for caregivers with children aged 1-10): breastfeeding until age two, consuming three meals per day with two snacks, discouraging low nutrient foods, food and handwashing, and encouraging vitamin-rich colorful foods.

Table 1. Salama Fahasalamana Curriculum and project measures - education topics, learning objectives, measurements and materials

\begin{tabular}{|c|c|c|}
\hline Week \& Topic & Learning Objectives & Measurements \& Materials \\
\hline $\begin{array}{l}\text { Week 1: } \\
\text { Importance of } \\
\text { breastfeeding and } \\
\text { consuming nutrient- } \\
\text { dense, colorful foods }\end{array}$ & $\begin{array}{l}\text { (1) List examples of } \\
\text { nutrient-dense and low- } \\
\text { nutrient foods } \\
\text { (2) Identify the benefits of } \\
\text { breastfeeding until } 2 \text { years } \\
\text { of age }\end{array}$ & $\begin{array}{l}\text { Baseline measurements collected } \\
\text { Counseling based on results of diet } \\
\text { diversity and knowledge } \\
\text { questionnaire } \\
\text { Handout } 1 \text { or } 2 \text { provided }\end{array}$ \\
\hline $\begin{array}{l}\text { Week 2: } \\
\text { Consuming low cost, in- } \\
\text { season fruits and } \\
\text { vegetables } \\
\text { Importance of foods that } \\
\text { provide energy for } \\
\text { strength and eye health }\end{array}$ & $\begin{array}{l}\text { (1) Identify less expensive } \\
\text { fruits and vegetables } \\
\text { available at the local } \\
\text { market } \\
\text { (2) List foods that keep you } \\
\text { strong and keep your eyes } \\
\text { healthy }\end{array}$ & $\begin{array}{l}\text { Individualized Counseling } \\
\text { Review of Handout pertaining to } \\
\text { Healthy Foods and Benefits }\end{array}$ \\
\hline $\begin{array}{l}\text { Week 3: } \\
\text { Importance of clean } \\
\text { water and good hygiene } \\
\text { practices } \\
\text { Reinforcement of } \\
\text { consuming nutrient- } \\
\text { dense foods }\end{array}$ & $\begin{array}{l}\text { (1) Demonstrate proper } \\
\text { handwashing to reduce the } \\
\text { spread of bacteria } \\
\text { (2) Identify the importance } \\
\text { of washing hands with } \\
\text { soap and food with treated } \\
\text { water. } \\
\text { (3) Replicate a simple and } \\
\text { nutritious snack for the } \\
\text { family }\end{array}$ & $\begin{array}{l}\text { Individualized Counseling } \\
\text { Handwashing Demonstration } \\
\text { Healthy Snack and Recipe Provided } \\
\text { Review of Handout pertaining to } \\
\text { Handwashing }\end{array}$ \\
\hline $\begin{array}{l}\text { Week 4: } \\
\text { Program acceptability } \\
\text { Goal setting and } \\
\text { changes in baseline } \\
\text { measurements }\end{array}$ & $\begin{array}{l}\text { (1) Recognize dietary } \\
\text { changes made and set goals } \\
\text { for improving health } \\
\text { behaviors }\end{array}$ & $\begin{array}{l}\text { End Measurements collected } \\
\text { Individualized Counseling }\end{array}$ \\
\hline
\end{tabular}




\section{Data analysis}

The survey data were analyzed using descriptive statistics and paired sample $t$-tests in Microsoft Excel (2010). A p value of $<0.05$ was considered statistically significant. Open-ended responses on program acceptability and behavior change were coded by two researchers, common responses identified, and frequency of common responses calculated.

\section{Results}

\section{Participant characteristics and nutritional status}

Participants $(\mathrm{n}=20)$ in the four-week Salama Fahasalamana program had a mean age of 37.5 $( \pm 14.7)$ years, all were female, and each was the grandmother or mother of the household. Manywere currently employed (60\%), had a primary education $(40 \%)$, and had children attending school (85\%). The average number of adults per household was $2.3( \pm 0.9)$, while the average number of children was $2.2( \pm 1.0)$. Most participants reported growing their own crops and/or raising their own livestock $(\mathrm{n}=14,70 \%)$ and of those, reported eating and selling the crops and/or livestock $(n=7,50 \%)$, strictly selling $(n=4,29 \%)$, and strictly eating $(n=3,21 \%)$. For BMI, the majority were within normal limits, followed by overweight, and underweight (40\%, 35\%, 25\% respectively), and for MUAC measurements, 25\% were below the normal limit.

\section{Diet diversity}

Comparing diet diversity pre- versus post- education, significant changes were found in the consumption of vitamin A rich foods for adults (Table 2), though significant changes were not found for children. There were no significant changes found in the overall diet diversity scores of children nor adults, and no significant changes found in the RRS scores (Table 2).

\section{Health knowledge and behaviors}

The treatment of drinking water did not significantly change (Table 2), but washing fruits and vegetables with treated water significantly increased $(\mathrm{p} \leq 0.01)$. Of those who began using treated water, 33\% used boiled water, and 67\% used sur'Eau. Sur'Eau is a chlorine solution used for water treatment in Madagascar and other countries.

Participants were provided with a list containing the options: diet diversity, cost, availability, child food preferences, what you normally buy, and health. When asked to select the three most important factors when shopping for food, participants reported health (30\%), cost (22\%), and child food preferences (18\%) most commonly. Participants were then provided with a list containing the options: ensuring cleanliness, containing vitamins, providing satiety, diet diversity, child food preferences, and providing energy. When asked to select the three most important factors when preparing food, participants reported providing energy (27\%), ensuring cleanliness $(27 \%)$, and containing vitamins (25\%). Diet diversity was selected least often as important $(3 \%)$.

Participants were asked to identify foods believed to be nutritious and not nutritious. Overall, more healthy foods were identified as nutritious, and lower nutrient foods as non-nutritious post assessment (Table 3).

When asked about household water, participants reported collecting tap water from community wells. All participants reported using this water for drinking, bathing, cooking, washing fruits 
Table 2. Changes in knowledge, health behaviors, and dietary measures by participants $(\mathrm{n}=20)$ enrolled in the Salama Fahasalamana Health and Nutrition Counseling Program in Andasibe, Madagascar

\begin{tabular}{|c|c|c|c|c|c|}
\hline Question & $\begin{array}{l}\text { Pre- } \\
\text { evaluation } \\
\text { Percentage }\end{array}$ & $\begin{array}{l}\text { Post } \\
\text { evaluation } \\
\text { Percentage }\end{array}$ & $\begin{array}{l}\text { Pre- } \\
\text { evaluation } \\
\text { Mean } \\
(\mathrm{SD})^{\mathrm{a}}\end{array}$ & $\begin{array}{l}\text { Post } \\
\text { evaluation } \\
\text { Mean } \\
(\mathrm{SD})^{\mathrm{a}}\end{array}$ & p value ${ }^{b}$ \\
\hline $\begin{array}{l}\text { Do you treat your drinking } \\
\text { water with anything before } \\
\text { you drink it? } \mathrm{N}=20 \\
1=\mathrm{No} \\
2=\text { Yes }\end{array}$ & $\begin{array}{l}5 \% \\
95 \% \\
\end{array}$ & $\begin{array}{l}0 \% \\
100 \% \\
\end{array}$ & $\begin{array}{l}1.9 \\
( \pm 0.22)\end{array}$ & $\begin{array}{l}2.0 \\
( \pm 0.1)\end{array}$ & 0.33 \\
\hline $\begin{array}{l}\text { How often do you treat the } \\
\text { water? } \mathrm{N}=19 \\
1=\text { Sometimes } \\
2=\text { Often } \\
3=\text { Always }\end{array}$ & $\begin{array}{l}11 \% \\
5 \% \\
84 \% \\
\end{array}$ & $\begin{array}{l}5 \% \\
10 \% \\
85 \% \\
\end{array}$ & $\begin{array}{l}2.6 \\
( \pm 0.9)\end{array}$ & $\begin{array}{l}2.8 \\
( \pm 0.5)\end{array}$ & 0.39 \\
\hline $\begin{array}{l}\text { Do you wash your fruit } \\
\text { and/or vegetables with } \\
\text { treated water? } \mathrm{N}=20 \\
1=\mathrm{No} \\
2=\text { Yes }\end{array}$ & $\begin{array}{l}100 \% \\
0 \% \\
\end{array}$ & $\begin{array}{l}70 \% \\
30 \% \\
\end{array}$ & $\begin{array}{l}1.0 \\
( \pm 0.1)\end{array}$ & $\begin{array}{l}1.3 \\
( \pm 0.5) \\
\end{array}$ & $\mathrm{p}<0.01$ \\
\hline $\begin{array}{l}\text { Vitamin A-rich F\&V Score } \\
\text { (caregiver) } \mathrm{N}=20 \\
1=\text { No } \\
2=\text { Yes }\end{array}$ & $\begin{array}{l}50 \% \\
50 \% \\
\end{array}$ & $\begin{array}{l}10 \% \\
90 \% \\
\end{array}$ & $\begin{array}{l}1.5 \\
( \pm 0.5)\end{array}$ & $\begin{array}{l}1.9 \\
( \pm 0.3)\end{array}$ & $\mathrm{p}<0.01$ \\
\hline $\begin{array}{l}\text { Vitamin A-rich F\&V Score } \\
\text { (child 2-10) } \mathrm{N}=16 \\
1=\mathrm{No} \\
2=\mathrm{Yes}\end{array}$ & $\begin{array}{l}44 \% \\
56 \%\end{array}$ & $\begin{array}{l}13 \% \\
88 \%\end{array}$ & $\begin{array}{l}1.6 \\
( \pm 0.5)\end{array}$ & $\begin{array}{l}1.9 \\
( \pm 0.3)\end{array}$ & 0.06 \\
\hline $\begin{array}{l}\text { Diet Diversity Questionnaire } \\
\text { Score (caregiver) } N=20\end{array}$ & & & $\begin{array}{l}4.1 \\
( \pm 1.0)\end{array}$ & $\begin{array}{l}4.5 \\
( \pm 1.3) \\
\end{array}$ & 0.22 \\
\hline $\begin{array}{l}\text { Diet Diversity Questionnaire } \\
\text { Score (child 2-10) } N=16\end{array}$ & & & $\begin{array}{l}4.2 \\
( \pm 1.2)\end{array}$ & $\begin{array}{l}4.6 \\
( \pm 1.3) \\
\end{array}$ & 0.19 \\
\hline $\begin{array}{l}\mathrm{RRS}^{\mathrm{c}} \text { Score } \mathrm{N}=20 \\
\text { Mean Score } \\
<\text { Low Intake } \\
\text { Low Intake } \\
\text { Moderate Intake } \\
\end{array}$ & $\begin{array}{l}10 \% \\
65 \% \\
25 \% \\
\end{array}$ & $\begin{array}{l}10 \% \\
75 \% \\
15 \% \\
\end{array}$ & $\begin{array}{l}21,138.8 \\
( \pm 9,025.5)\end{array}$ & $\begin{array}{l}20,999.9 \\
( \pm 9,484.9)\end{array}$ & 0.93 \\
\hline
\end{tabular}

${ }^{\text {aStandard Deviation }}$

${ }^{\mathrm{b}}$ Fruit and Vegetables

${ }^{\mathrm{c}}$ Resonance Raman Spectroscopy 
and vegetables, washing meat to cook, and washing household dishes and utensils, while other uses were washing clothes (50\%), and giving to animals (45\%). All washed hands, "more than once a day". Most participants reported keeping soap in the house $(85 \%)$.

Table 3. Frequently reported foods identified as nutritious and non-nutritious by participants enrolled in the Salama Fahasalamana Health and Nutrition Counseling Program in Andasibe, Madagascar $(\mathrm{n}=20)$.

\begin{tabular}{|c|c|c|c|}
\hline \multicolumn{2}{|c|}{ Food Items Pre Nutrition Education } & \multicolumn{2}{|c|}{ Food Items Post Nutrition Education } \\
\hline \multicolumn{2}{|c|}{ Nutritious } & \multicolumn{2}{|c|}{ Nutritious } \\
\hline Answer & $\%$ & Answer & $\%$ \\
\hline Vegetables & $22 \%$ & Vegetables & $24 \%$ \\
\hline Fish & $10 \%$ & Leafy Greens & $11 \%$ \\
\hline Meat & $08 \%$ & Beans & $11 \%$ \\
\hline \multicolumn{2}{|c|}{ Non-Nutritious } & \multicolumn{2}{|c|}{ Non-Nutritious } \\
\hline Answer & $\%$ & Answer & $\%$ \\
\hline Cassava & $32 \%$ & Processed Crackers & $21 \%$ \\
\hline Sweet Potatoes & $14 \%$ & Cassava & $17 \%$ \\
\hline Leafy Greens & $08 \%$ & Pasta & $15 \%$ \\
\hline
\end{tabular}

Responses calculated by asking participants to list the top three foods believed to be nutrition and non-nutritious. Percentages based on responses of agreement.

\section{Open-ended questions}

All 20 caregivers participated in the open-ended response questions on program acceptability. More than half perceived the education on handwashing and water treatment, and the importance of consuming colorful vegetables as the most helpful program aspect. All but one (95\%) reported making at least one dietary change. The majority $(80 \%)$ of changes were increased diet diversity. The main barrier reported for not making further changes was financial (95\%), and reported wanting further education on health, cooking methods, agricultural techniques, and raising healthy children. There were no reports of unhelpful information.

\section{Discussion}

This pilot study suggested that tailored health education was effective for increasing diet diversity and health practices in a limited-resource area of Madagascar. In the baseline survey and a previous study (Farris et al., 2019), diet diversity was not found to be of importance to caregivers. In the post survey however, diet diversity was more valued as shown by the increases in vitamin A rich food consumption and open-ended response feedback, but not dietary diversity or RRS scores. Increases were not significant for children. This could be due to the small sample size, or the short duration of the intervention period, though other studies have found significant increases over short duration periods (Aguilar et al., 2014; Scarmo et al., 2013). However, this study supports that tailored education which encourages the consumption of vitamin A rich foods can be effective, and emphasis on an intervention with a longer study duration and larger sample size is warranted to obtain an accurate evaluation of changes.

A misconception of the definition of nutritious food has been shown in this and previous studies (Farris et al., 2019; Rakotosamimanana et al., 2014). This study revealed that knowledge can be affected through targeted education. For example, leafy greens were frequently listed as non- 
nutritious before education but identified to be nutritious post education. Packaged crackers were also listed frequently as non-nutritious post education due to encouragement on limiting processed food items. In Andasibe, beans are more affordable and available than animal sourced protein, and the current study highlighted them as good protein sources and encouraged consumption as part of the education provided. Studies have reported that Malagasy recognize the importance of consuming meat and seafood (Asgary et al., 2015; Farris et al., 2019; Rakotosamimanana et al., 2014), but consumption is scarce due to high costs. In this study, beans were more frequently listed as a nutritious food post education instead of meat and fish. These findings reinforce that health education may shape how individuals spend their limited income to target nutritionally dense foods, ultimately influencing health using the resources available.

The education provided in the current study had a significant influence on the number of households that began using treated water to wash fruits and vegetables before consumption. Tap water obtained from local community wells is common in rural areas, as is collecting surface water from lakes, rivers, and streams (World Food Program, 2010). Treating water before use is crucial because it could contain possible runoff from animal and human feces as well as other contaminants leading to health consequences (World Food Program, 2010). Poor sanitation practices have been linked to increased morbidity, meaning the improvement of water treatment practices and handwashing could affect spread of disease (World Food Program, 2010). For example, toxoplasmosis, a disease caused by the Toxoplasma gondii parasite (Flegr et al., 2014), has potential to cause encephalopathy in the fetus of an infected mother. This disease, primarily spread by feline defecation, is a concern for the Malagasy population, given that wild and domestic cats and dogs are prevalent without boundaries (Czaja et al., 2015). According to a study that analyzed Toxoplasma antibodies in pregnant women in Madagascar, $84 \%$ of women of childbearing age had been exposed to latent toxoplasmosis (Bobic et al., 1995; Flegr et al., 2014). Either boiling or using Sur'Eau drops is low cost in this area.

Due to the influences of the nearby Andasibe-Mantadia National Park, namely the limitation of natural resource use and/or economic influences, these results may not be generalizable to other areas. Survey bias may exist due to language or cultural differences. Longer duration and a larger sample would be required to assess the potential for changing health of the study population and other regions. A strength of the current study was the collaboration with and training of community health professionals in the Andasibe region to promote sustainability.

Health and nutrition counseling programs can be successful in increasing dietary diversity and water treatment practices among caregivers in limited-resource areas. Opportunities for further education include increasing knowledge of nutrient dense foods, expanding food choice beyond carbohydrate-rich foods, the importance of diet diversity, and sustaining education efforts beyond project implementation. The findings from the current study support the evidence that health and nutrition counseling programs with individualized approaches can improve diet diversity and increase health knowledge, and strategies highlighted in this research can inform others working in limited-resource areas.

Acknowledgements: Many students at Appalachian State University helped with data collection for this project: Olivia Caldwell, Ali Collins, Sarah Radman, Laura Thompson, Erin Jameson, Eavan Jennings, Ilya Wang, Michelle Tibbett, and Kelsey Hawkins. 
Funding: the following scholarships were awarded to the first author to support travel: the Pamela Hardin Fund, the Balfour Beatty Fund, and the Maria Winkler Hymans Endowed Scholarship

Conflict of Interest: None.

\section{References}

Aguilar S, Wengreen H, Lefevre M, Madden G, Gast J. (2014). Skin Carotenoids: A Biomarker of Fruit and Vegetable Intake in Children. J Acad Nutr Diet. 114(8):1174-1180. doi.org/10.1016/j.jand.2014.04.026

Asgary R, Liu M, Naderi R, Grigoryan Z, Malachovsky M. (2015). Malnutrition prevalence and nutrition barriers in children under 5 years: A mixed methods study in Madagascar. Int Health. 7(6):426-432. doi: 10.1093/inthealth/ihv016

Association Mitsinjo. (2019). Nature-based tourism, conservation, and research in Andasibe, Madagascar. https://associationmitsinjo.wordpress.com/news/

Black RE, Victora CG, Walker SP, Bhutta Z, Christian P, de Onis M, Uauy, R. (2013). Maternal and child undernutrition and overweight in low-income and middle-income countries. Lancet. 382(9890):427-451. doi:10.1016/S0140-6736(13)60937-X.

Bobic B, Nikolic A, Klun I, Djurkovic-Djakovic O, et al. (1995). Prevalence of toxoplasmosis in a population of pregnant women in Antananarivo (Madagascar). Bull Soc Pathol Exot Fil. 88:4649. https://www.ncbi.nlm.nih.gov/pubmed/7787454.

Czaja R, Wills A, Hanitriniaina S, Reuter KE, Sewall BJ. (2015). Consumption of domestic cat in madagascar: Frequency, purpose, and health implications. Anthrozoos. 28(3):469-482. doi: $10.1080 / 08927936.2015 .1052280$

Farris A, Misyak S, O'Keefe K, VanSicklin L, Porton I. (2019). Understanding the drivers of food choice and barriers to a diverse diet in Madagascar. J Hunger Environ Nutr. 15(3):388-400. DOI: $10.1080 / 19320248.2019 .1566110$.

Flegr J, Prandota J, Sovičková M, \& Israili ZH. (2014). Toxoplasmosis - A global threat. Correlation of latent toxoplasmosis with specific disease burden in a set of 88 countries. PLoS One. 9(3). doi: 10.1371/journal.pone.0090203

Headrick E, Rist C, Zohdy S, et al. (2014). Factors affecting community health volunteer utilization around Ranomafana National Park, Madagascar. Ann Glob Heal. 80(3):237. doi: 10.1016/j.aogh.2014.08.199

Kennedy G, Ballard T, Dop M. (2013). Guidelines for Measuring Household and Individual Dietary Diversity. Nutrition and Consumer Protection Division, Food and Agriculture Organization. http://www.fao.org/fileadmin/user upload/wa workshop/docs/FAO-guidelinesdietary-diversity2011.pdf

Khan AZ, Rafique G, Qureshi H, Badruddin S. (2013). A Nutrition Education Intervention to Combat Undernutrition: Experience from a Developing Country. International Scholarly Research Notices. 1-7. DOI: 10.5402/2013/210287. 
Metta E, Nyato DJ, Haisma H, et al. (2014). Public policy, health system, and community actions against illness as platforms for response to NCDs in Tanzania: a narrative review. Glob Health Action. 7(1):23439. doi: 10.3402/gha.v7.23439

Müller O Krawinkel M. (2005). Malnutrition and health in developing countries. CMAJ. 173(3):279-286. doi: 10.1503/cmaj.050342

Mushaphi LF, Dannhauser A, Walsh CM, Mbhenyane X, Rooyan FC. (2017). The impact of a nutrition education programme on feeding practices of caregivers with children aged 3 to 5 years in rural Limpopo province, South Africa. South African J Clin Nutr. 30(4):101-108. doi: $10.1080 / 16070658.2017 .1322823$

Rakotosamimanana VR, Arvisenet G, Valentin D. (2014). Studying the nutritional beliefs and food practices of Malagasy school children parents. A contribution to the understanding of malnutrition. Appetite. 81:67-75. doi: 10.1016/j.appet.2014.05.032

Ruel MT, Deitchler M, Arimond M. (2010). Developing Simple Measures of Women's Diet Quality in Developing Countries: Overview. J Nutr. 140(11):2048S-2050S. doi: 10.3945/jn.110.123695

Sanchez, P. (2005). Halving Hunger: It Can be Done: Summary Version. University of California, Berkeley: United Nations Millennium Project.

Scarmo S, Cartmel B, Lin H, Leffell D, Ermakov I, et al. (2013). Single v. multiple measures of skin carotenoids by resonance Raman spectroscopy as a biomarker of usual carotenoid status. British J of Nutr. 110(5)911-917. doi: 10.1017/S000711451200582X

Sethi V, Kashyap S, Seth V. (2003). Effect of nutrition education of mothers on infant feeding practices. Indian J Pediatr. 70(6):463-466. doi: 10.1007/BF02723133

Sharp, M, Kruse I. (2011). Health, Nutrition, and Population in Madagascar, 2000-09. Washington, DC: The World Bank. doi: 10.1596/978-0-8213-8538-8

United States Agency for International Development. Nourishing Lives \& Building the Future: The History of Nutrition at USAID. 2019. https://www.usaid.gov/sites/default/files/documents/1864/HON_Report_web_pages-508Final.pdf

World Bank. The World Bank in Madagascar. 2019. https:/www.worldbank.org/en/country/madagascar/overview

World Food Program. (2010). Comprehensive Food and Nutrition Security and Vulnerability Analysis.

https://www.humanitarianlibrary.org/sites/default/files/2013/07/Madagascar_CFSVA\%2BN.pdf

World Health Organization. Healthy Diet. 2020. https:/www.who.int/news-room/factsheets/detail/healthy-diet

Zidichouski JA, Mastaloudis A, Poole SJ, et al. (2009). Clinical validation of a noninvasive, Raman spectroscopic method to assess carotenoid nutritional status in humans. J Am Coll Nutr. 28(6):687-693. doi: 10.1080/07315724.2009.10719802 